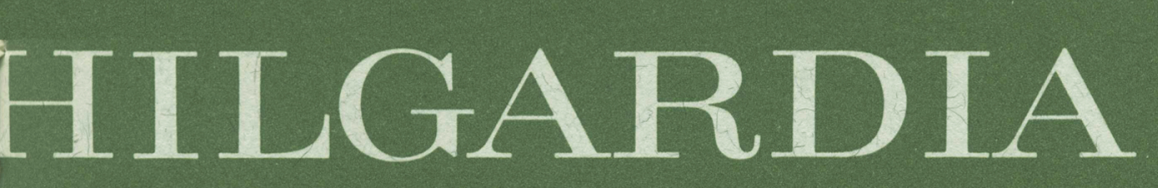

JOURNAL OF AGRICULTURAL SCIENCE PUBLISHED BY HE CALIFORNIA AGRICULTURAL EXPERIMENTSTATION

Volume $52 \cdot$ Number $6 \bullet$ June 1984

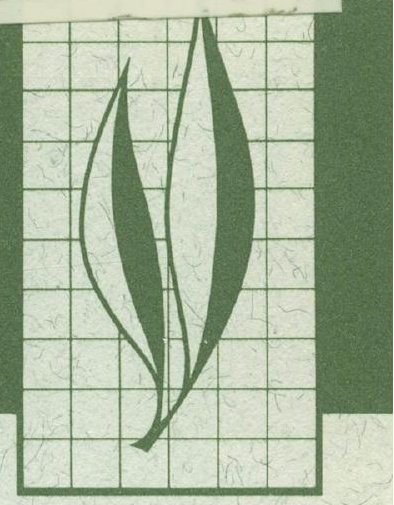

\title{
Early Stage Infiltration of Water into Horizontal and Vertical Soil Columns
}

T. Miyazaki, D. R. Nielsen, and J. L. MacIntyre 


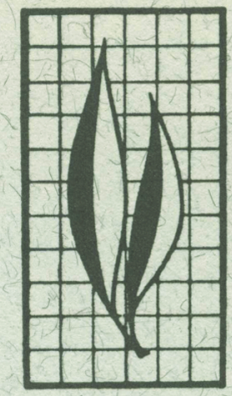

Water content distributions during horizontal, vertical-up, and vertical-down infiltration into air-dry soil, were measured experimentally using gamma radiation attenuation equipment. A sufficient number of soil columns were analyzed to ascertain fiducial limits of both measured and calculated soil water properties and parameters. The first three coefficient functions of Philip's solution of the Richards' flow equation applied to infiltration as well as to the soil hydraulic conductivity and soil water diffusivity as functions of soil water content were ascertained from the measured water content distributions.

THE AUTHORS:

T. Miyazaki, former Visiting Scientist, is presently an Agricultural Engineer, Shikoku Agricultural Experiment Station, Ikano-cho, Zentsuji-shi, Kagawa-ken, Japan. D. R. Nielsen is Professor of Soil and Water Science, Land, Air, and Water Resources, and Soil and Water Scientist in the Experiment Station, University of California, Davis. J. L. MacIntyre is Staff Research Associate, Land, Air, and Water Resources, University of California, Davis. 


\section{Early Stage Infiltration of Water into Horizontal and Vertical Soil Columns ${ }^{1}$}

\section{INTRODUCTION}

'THE MOST COMPREhENSIVE solutions of the Richards' flow equation applied to horizontal and vertical infiltration were given by Philip (1955, 1957a, 1957b, 1969a, 1969b). Philip's solutions as well as numerical methods have been used to predict soil water content distributions and cumulative infiltrations. On the other hand, relatively few analytical studies of actual water content distributions for vertical infiltration into soils have been reported. To complete the theory of infiltration, several experimental analyses commensurate with the above theory should be carried out. Nielsen and Vachaud (1965) measured water content vs time using the distance as a parameter and estimated the coefficients in Philip's solution of the infiltration equation. They suggested that additional investigations to relate these coefficients to various soil-physical parameters, such as hydraulic conductivity and diffusivity, are necessary. The first purpose of this study was to evaluate experimentally the first three coefficient functions of Philip's solution, using sufficient numbers of horizontal, vertical-down, and vertical-up flow data. The second purpose of this study was to determine the soil-hydraulic properties from the flow data.

\section{THEORETICAL CONSIDERATION}

The equations for horizontal, vertical-down, and vertical-up water flow in a homogeneous soil are written, respectively, as

$$
\begin{aligned}
& \frac{\partial \theta}{\partial t}=\frac{\partial}{\partial x_{1}}\left(D \frac{\partial \theta}{\partial x_{1}}\right) \\
& \frac{\partial \theta}{\partial t}=\frac{\partial}{\partial x_{2}}\left(D \frac{\partial \theta}{\partial x_{2}}\right)-\frac{\partial K}{\partial x_{2}} \\
& \frac{\partial \theta}{\partial t}=\frac{\partial}{\partial x_{3}}\left(D \frac{\partial \theta}{\partial x_{3}}\right)+\frac{\partial K}{\partial x_{3}}
\end{aligned}
$$

where $\theta$ is the volumetric soil water content $\left(\mathrm{cm}^{3} / \mathrm{cm}^{3}\right), \mathrm{t}$ the time $(\mathrm{min}), \mathrm{x}$ the horizontal distance $(\mathrm{cm}), \mathrm{x}_{2}$ the vertical distance positive downward, $\mathrm{x}_{3}$ the vertical distance 
positive upward, $\mathrm{K}$ the unsaturated hydraulic conductivity $(\mathrm{cm} / \mathrm{min})$, and $\mathrm{D}$ the hydraulic diffusivity $\left(\mathrm{cm}^{2} / \mathrm{min}\right)$ defined as

$$
D=K \frac{d h}{d \theta}
$$

where $\mathrm{h}$ is the pressure head $(\mathrm{cm})$.

Solutions of these equations for semi-infinite soil under the condition

$$
\begin{array}{ll}
\theta=\theta_{i}, & t=0, \quad x_{n}>0 \\
\theta=\theta_{0}, & t \geqq 0, \quad x_{n}=0
\end{array}
$$

for $\mathrm{n}=1,2$, or 3 were given by Philip $(1957 \mathrm{a}, 1969 \mathrm{~b})$ as follows:

$$
\begin{aligned}
& x_{1}=\phi t^{\frac{1}{2}} \\
& x_{2}=\phi t^{\frac{1}{2}}+\chi t+\psi t^{\frac{3}{2}}+w t^{2}+\ldots \\
& x_{3}=\phi t^{\frac{1}{2}}-x t+\psi t^{\frac{3}{2}}-w t^{2}+\ldots
\end{aligned}
$$

where $\theta_{\mathrm{i}}$ is the initial soil water content, $\theta_{0}$ is a larger water content at the plane of water entry, and the coefficients $\phi, \chi, \psi$, and $\omega$ are unique functions of $\theta$. These three solutions express the soil water distributions during horizontal, vertical-down, and verticalup infiltration, respectively.

Philip (1955, 1957a, 1957b) provided a procedure for computing the coefficients $\phi, \chi$, $\psi$, and $\omega$ from given values of $\mathrm{D}$ and $\mathrm{K}$ as functions of $\theta$. From these coefficients, the soil water distribution curves can be predicted. Youngs (1957) and Nielsen, Kirkham, and van Wijk (1961) showed that moisture distribution curves calculated from eq. (7) agreed well with values measured in the laboratory and in the field, respectively.

Instead of calculating the three unknown coefficients $\phi, \chi$, and $\psi$ from experimentally derived $\mathrm{D}(\theta)$ and $\mathrm{K}(\theta)$ functions, it is also possible to estimate these three parameters from horizontal, vertical-down, and vertical-up infiltration data using eqs. (6), (7), and (8) neglecting the fourth and higher terms. For such data the experimental equations for infiltration may be written as

$$
\begin{aligned}
& x_{1}(\theta, t)=t^{\frac{1}{2}} \phi(\theta)+\varepsilon_{1} \\
& x_{2}(\theta, t)=t^{\frac{1}{2}} \phi(\theta)+t \chi(\theta)+t^{\frac{3}{2}} \psi(\theta)+\varepsilon_{1}+\varepsilon_{2} \\
& x_{3}(\theta, t)=t^{\frac{1}{2}} \phi(\theta)-t \chi(\theta)+t^{\frac{3}{2}} \psi(\theta)+\varepsilon_{1}+\varepsilon_{3}
\end{aligned}
$$

where $\varepsilon_{1}$ is the experimental error term which can be regarded as common in different directions of infiltration. Error terms $\varepsilon_{2}$ and $\varepsilon_{3}$ are 


$$
\begin{aligned}
& \varepsilon_{2}=t^{2} \omega(\theta)+t^{\frac{5}{2}} \gamma(\theta)+\ldots \\
& \varepsilon_{3}=-t^{2} \omega(\theta)+t^{\frac{5}{2}} \gamma(\theta)-\ldots .
\end{aligned}
$$

which denote the error by the truncation of the higher terms of eqs. (7) and (8). Even if $\varepsilon_{2}$ and $\varepsilon_{3}$ are clearly functions of $\theta$, and the contents of $\varepsilon_{1}$ are not clear, it is tenable to view $\varepsilon_{1}, \varepsilon_{2}$, and $\varepsilon_{3}$ as normally distributed functions having mean values of zero in this model.

When $\varepsilon_{1}, \varepsilon_{2}$, and $\varepsilon_{3}$ are negligibly small, the coefficients $\phi, \chi$, and $\psi$ can be calculated as unique functions of $\theta$. Philip (1955, 1957a, 1957b) derived the relation between these coefficients and $\mathrm{D}$ or $\mathrm{K}$ :

$$
\begin{aligned}
& \int_{\theta_{i}}^{\theta} \phi d \theta=-2 D \frac{d \theta}{d \phi} \\
& \int_{\theta_{i}}^{\theta} x d \theta=D\left(\frac{d \theta}{d \phi}\right)^{2} \frac{d \chi}{d \theta}+K-K_{i}
\end{aligned}
$$

Substituting eq. (14) into (15), we obtain

$$
K-K_{i}=\int_{\theta_{i}}^{\theta} \chi d \theta+\left.\frac{1}{2} \frac{d \chi}{d \phi}\right|_{\theta} \int_{\theta_{i}}^{\theta} \phi d \theta
$$

Equations (14) and (16) suggest that both $\mathrm{D}$ and $\left(\mathrm{K}-\mathrm{K}_{\mathrm{i}}\right)$ as functions of $\theta$ can be calculated from experimental observations of $\phi(\theta)$ and $\chi(\theta)$.

Transposing the terms in eq. (16) and evaluating the equation at $\theta=\theta_{0}$, we obtain

$$
k_{i}+\int_{\theta_{i}}^{\theta_{0}} \chi d \theta=k_{0}-\left.\frac{1}{2} \frac{d \chi}{d \phi}\right|_{\theta_{0}} \int_{\theta_{i}}^{\theta_{0}} \phi d \theta
$$

The left-hand side of eq. (17) constitutes the second parameter (A) of Philip's infiltration equation (Philip 1957b)

$$
I=S t^{\frac{1}{2}}+A t+B t^{\frac{3}{2}}+C t^{2}+\cdots
$$

where I is the cumulative infiltration, and $\mathrm{S}$ is the first parameter called the sorptivity. Corresponding to eq. (10), the three parameter infiltration equation may be written as

$$
I=S(\theta) t^{\frac{1}{2}}+A(\theta) t+B(\theta) t^{\frac{3}{2}}+m
$$

$S, A$, and $B$ are defined as

$$
S=\int_{\theta_{i}}^{\theta} 0 d \theta
$$




$$
\begin{aligned}
& A=\int_{\theta_{i}}^{\theta_{0}} \chi d \theta+K_{i} \\
& B=\int_{\theta_{i}}^{\theta_{0}} \psi d \theta
\end{aligned}
$$

$\mathrm{m}$ is a function of $\theta$, but we view it to be a normally distributed function having mean value of zero. Therefore, from eqs. (17) and (21) we obtain the relation

$$
A=K_{0}-\left.\frac{s}{2} \frac{d \chi}{d \phi}\right|_{\theta_{0}}
$$

Equation (23) implies that $A$ is not equal to $K_{0}$ unless $d \chi / d \phi$ is zero at $\theta=\theta_{0}$, and that it can be calculated if $\phi(\theta), \chi(\theta)$ and $\mathrm{K}_{\mathrm{O}}$ are known.

\section{EXPERIMENTAL METHOD}

\section{Gamma radiation attenuation equipment}

Gamma radiation attenuation equipment was used to measure the soil bulk density and soil water content. The radiation source was $\mathrm{Cs}^{137}$. Gamma-ray was collimated into a narrow beam by a window, made of lead, which was $2 \mathrm{~mm}$ wide and $5 \mathrm{~mm}$ high. The scintillation detector was a thallium-activated $\mathrm{NaI}$ crystal with photomultiplier and pulse-height analyzer-scaler.

The resolving time or dead time of a gamma radiation counting system is defined as the minimum time that can separate two consecutively recorded photons. An observed counting rate can be corrected for resolving time with the equation

$$
I=\frac{R}{1-T R}
$$

where $I$ is the true counting rate $(\mathrm{cpm}), \mathrm{R}$ is the observed counting rate (cpm) and $T$ is the resolving time ( $\mathrm{min} /$ count).

The mass absorption coefficient $\mu\left(\mathrm{cm}^{2} / \mathrm{g}\right)$ is the fraction of the original intensity removed from the beam per unit linear thickness of absorber defined as

$$
\ln \left(I / I_{0}\right)=-\mu \rho X
$$

where $I_{O}$ is the true counting rate through air $(\mathrm{cpm}), \varrho$ the density of the material $\left(\mathrm{g} / \mathrm{cm}^{3}\right)$, and $\mathrm{X}$ its thickness $(\mathrm{cm})$. When there are two or more materials, the equation is written as

$$
\ln \left(I / I_{0}\right)=-\sum_{i=1}^{n} \mu_{i} \rho_{i} X_{i}
$$


where $\mathrm{n}$ is the number of materials for a given resolving time $\mathrm{T}$, the mass absorption coefficient was found by plotting $\ell$ n I vs X. To find better estimations of $\mu$ and T, arbitrary resolving times were assumed to compare the resultant $\mu$ values with the theoretical values given by Reginato and van Bavel (1964). Correlation coefficients of the linear regression lines between 1n I vs X and the weighted variances (Fritton 1969) of the points from the lines were calculated.

Hanford sandy loam surface soil, distilled water, an alminium block, glass plates, and acrylic plastic plates were used to determine the resolving time of the detector and mass absorption coefficients of the experimental materials.

\section{Material and procedure}

The air-dry soil sieved to pass through $2 \mathrm{~mm}$ screen was packed by hand in $5.68 \mathrm{~cm}$ inside diameter and $37.5 \mathrm{~cm}$ length acrylic plastic cylinders with small pin holes through their walls to maintain the soil air at atmospheric pressure.

Soil was added to each cylinder in increments of approximately $30 \mathrm{~g}$. Each incremental addition to the cylinder was tapped with a wood mallet. After each tapping the surface soil was slightly stirred to provide continuity with each soil addition. The average soil bulk density of each column was calculated from the total volume and the total oven-dry weight of soil. Bulk density values were measured at $1-\mathrm{cm}$ intervals along the column from gamma radiation counting rates applying eq. (26) for three materials

$$
\left.\rho_{b}=-\frac{1}{L\left(\mu_{w} w_{i}+\mu_{s}\right)}\left[\ln \left(I / I_{o}\right)+\mu_{p} y \rho_{p}\right)\right]
$$

where $\varrho_{b}$ and $\varrho_{p}$ are the soil bulk density and the density of the acrylic plastic column, respectively; $\mathrm{L}$ the inside diameter of the column; $\mu_{\mathrm{w}}, \mu_{\mathrm{s}}$, and $\mu_{\mathrm{p}}$ the mass absorption coefficients of water, soil, and plastic, respectively; $w_{i}$ the initial soil water content by weight; and y the thickness of the plastic wall.

To initiate infiltration into the air-dry soil, the column was placed vertically upside down and the bottom glassbead plate removed without disturbing the soil. After the plate was filled with distilled water and connected with a water reservoir it was replaced firmly on top of the soil, maintaining the water pressure of the plate from 0 to $-5 \mathrm{~cm}$. The air entry value of the glassbead plate was $-20 \mathrm{~cm}$. Zero time for infiltration was considered the instant the glassbead plate touched the soil surface. The column was rapidly positioned to stand vertically or horizontally in the gamma-ray attenuation apparatus.

During infiltration, a constant pressure of $-5 \mathrm{~cm}$ at the center of the glassbead plate was maintained for all runs. Visual wetting front distances from the entrance of water were measured repeatedly. Gamma radiation counts collected in 10 second intervals at each $1 \mathrm{~cm}$ distance along the column were measured to calculate soil water content distributions at specific times.

Water content values were calculated by the equation

$$
\theta=-\frac{1}{\mu_{w} \rho_{w} L} \ln \left(I / I_{s}\right)+\theta_{i}
$$

where $I_{s}$ is the true counting rate through air-dry soil within the column. To calculate the true water content profile at each time, a correction was made that accounted for the 
time required for observing each gamma attenuation measurement as well as the positioning of the gamma beam at specific locations along the column' ${ }^{1}$. Hence, all the data $\mathbf{x}(\theta)$ were corrected with the equation

$$
\hat{x}\left(t_{i}\right)=x\left(t_{i}+\Delta t_{i}\right)-\frac{x\left(t_{i}+\Delta t_{i}\right)-x\left(t_{i-1}+\Delta t_{i-1}\right)}{\left(t_{i}+\Delta t_{i}\right)-\left(t_{i-1}+\Delta t_{i-1}\right)} \Delta t_{i}
$$

where $\hat{\mathbf{x}}\left(\mathrm{t}_{\mathrm{i}}\right)$ is the corrected distance at which the water content is $\theta, \mathbf{x}\left(\mathrm{t}_{\mathrm{i}}+\Delta \mathrm{t}_{\mathrm{i}}\right)$ is the measured distance at time $\left(t_{i}+\Delta t_{i}\right), \Delta t_{i}$ is the lag from time $t_{i}$ which arises from the procedure of the measurement, $x\left(t_{i-1}+\Delta t_{i-1}\right)$ is the last measured distance at time $\left(\mathrm{t}_{\mathrm{i}}+\Delta \mathrm{t}_{\mathrm{i}-1}\right)$, and $\Delta \mathrm{t}_{\mathrm{i}-1}$ is the time lag which is not equal to $\Delta \mathrm{t}_{\mathrm{i}}$. For example, in horizontal infiltration, let's choose $t_{1}=30 \mathrm{~min}$ and $t_{2}=60 \mathrm{~min}$. For $\theta=0.10, \Delta t_{1}=3.3 \mathrm{~min}$ and $\Delta \mathrm{t}_{2}=4.2 \mathrm{~min}$. Substituting them into eq. (26), we obtain the following equation for $\theta=0.10$,

$$
\hat{x}(60)=x(64.2)-\frac{x(64.2)-x(33.3)}{64.2-33.3} 4.2
$$

The maximum difference between the measured and calculated distance in this experiment was $0.5 \mathrm{~cm}$.

\section{RESULTS}

\section{Resolving time and mass absorption coefficient}

Figure 1 shows the logarithm of the counting rate plotted against thickness of distilled water. The linear regression lines were drawn in figure 1 for each resolving time. Table 1 gives the resolving times, mass absorption coefficients, the correlation coefficients of each regression line, the weighted variances which were defined by Fritton (1969), and the theoretical mass absorption coefficients. Comparing these data, $15.0 \mu \mathrm{sec} /$ count resolving time gave the closest absorption coefficient values to the theoretical values and

Fig. 1. Corrected and uncorrected counting rates vs thickness of distilled water. The slope of the graph is equal to the mass absorption coefficient for water.

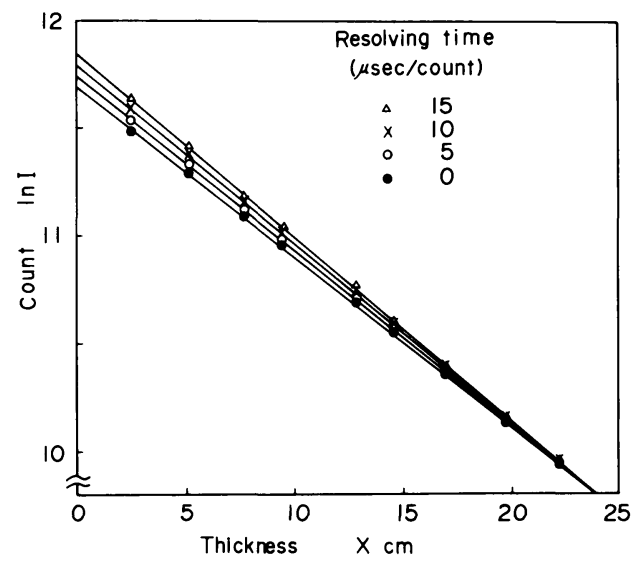


it provided larger correlation coefficients of the regression lines compared with those for uncorrected lines. Therefore, even if it seems slightly larger than T values reported in the literature, $15.0 \mu \mathrm{sec} /$ count was used in this experiment as the best resolving time for all the materials.

\section{Bulk density}

Table 2 shows bulk density values for each column, calculated from gamma radiation attenuation as well as measured directly by weighing the total oven-dry soil in each

\section{TABLE 1. RESOLVING TIME AND MASS ABSORPTION COEFFICIENTS}

\begin{tabular}{|c|c|c|c|c|c|c|}
\hline Material & $\begin{array}{c}\text { Density } \\
\mathrm{g} / \mathrm{cm}^{3}\end{array}$ & $\begin{array}{l}\text { Resolving } \\
\text { time } \\
\mu \text { sec/count }\end{array}$ & $\begin{array}{c}\text { Mass } \\
\text { absorption } \\
\text { coefficient } \\
\mathrm{cm}^{2} / \mathrm{g}\end{array}$ & $\begin{array}{l}\text { Correlation } \\
\text { coefficient }\end{array}$ & $\begin{array}{l}\text { Weighted } \\
\text { variance }\end{array}$ & $\begin{array}{c}\text { Theoretical } \\
\text { mass absorption } \\
\text { coefficient } \\
\mathrm{cm}^{2} / \mathrm{g}\end{array}$ \\
\hline \multirow{4}{*}{$\begin{array}{l}\text { Distilled } \\
\text { water }\end{array}$} & \multirow[t]{4}{*}{1.000} & 0 & 0.0793 & -0.99984 & 32.89 & \multirow[t]{4}{*}{0.0862} \\
\hline & & 5 & 0.0812 & -0.99990 & 19.92 & \\
\hline & & 10 & 0.0833 & -0.99993 & 14.97 & \\
\hline & & 15 & 0.0855 & -0.99993 & 21.52 & \\
\hline \multirow[t]{2}{*}{ Hanford soil } & \multirow[t]{2}{*}{1.420} & 0 & 0.0671 & & & \multirow[t]{2}{*}{0.0775} \\
\hline & & 15 & 0.0798 & & & \\
\hline \multirow{2}{*}{$\begin{array}{l}\text { Aluminum } \\
\text { block }\end{array}$} & \multirow[t]{2}{*}{2.775} & 0 & 0.0723 & & & \multirow[t]{2}{*}{0.0748} \\
\hline & & 15 & 0.0748 & & & \\
\hline \multirow[t]{2}{*}{ Glass plate } & \multirow[t]{2}{*}{2.478} & 0 & 0.0697 & -0.99986 & & \\
\hline & & 15 & 0.0757 & -0.99990 & & \\
\hline \multirow{2}{*}{$\begin{array}{c}\text { Plastic } \\
\text { plate }\end{array}$} & \multirow[t]{2}{*}{1.193} & 0 & 0.0714 & -0.99973 & & \\
\hline & & 15 & 0.0821 & -0.99983 & & \\
\hline
\end{tabular}

TABLE 2. BULK DENSITY VALUES FOR EACH SOIL COLUMN

\begin{tabular}{lccccc}
\hline $\begin{array}{c}\text { Direction } \\
\text { of } \\
\text { infiltration }\end{array}$ & $\begin{array}{c}\text { Column } \\
\text { number }\end{array}$ & $\begin{array}{c}\text { Calculated } \\
\text { bulk } \\
\text { density } \\
\left(\mathrm{g} / \mathrm{cm}^{3}\right)\end{array}$ & $\begin{array}{c}\text { True bulk } \\
\text { density } \\
\left(\mathrm{g} / \mathrm{cm}^{3}\right)\end{array}$ & $\begin{array}{c}\text { Standard } \\
\text { deviation }\end{array}$ & $\begin{array}{c}\text { Differences } \\
\text { of bulk } \\
\text { densities } \\
\left(\mathrm{g} / \mathrm{cm}^{3}\right)\end{array}$ \\
\hline Horizontal & 1 & 1.351 & 1.395 & 0.043 & 0.044 \\
& 3 & 1.371 & 1.401 & 0.025 & 0.030 \\
& 3 & 1.365 & 1.395 & 0.032 & 0.030 \\
\hline Vertical down & 5 & 1.328 & 1.402 & 0.025 & 0.074 \\
& 6 & 1.321 & 1.402 & 0.033 & 0.081 \\
\hline \multirow{2}{*}{ Vertical up } & 8 & 1.310 & 1.399 & 0.030 & 0.089 \\
& 9 & 1.324 & 1.401 & 0.034 & 0.077 \\
\hline Average & & & 1.401 & & 0.028 \\
Standard error & & & 0.004 & & \\
\hline
\end{tabular}


column. The calculated values underestimate the bulk density of all columns. These discrepancies may be attributed to the overestimation of the resolving time or the overestimation of the mass absorption coefficient of the soil. All values of the calculated bulk density from gamma radiation attenuation were corrected by adding the differences shown in table 2 in each column.

The average bulk density of all columns was $1.401 \mathrm{~g} / \mathrm{cm}^{3}$ with a standard error of $0.004 \mathrm{~g} / \mathrm{cm}^{3}$. The standard deviation of the bulk density within each column, estimated from each $1 \mathrm{~cm}$ counting rate for each column, ranged from 0.02 to $0.04 \mathrm{~g} / \mathrm{cm}^{3}$. This means that it is easier to prepare soil columns of the same bulk density than to pack a single column as uniformly as possible.

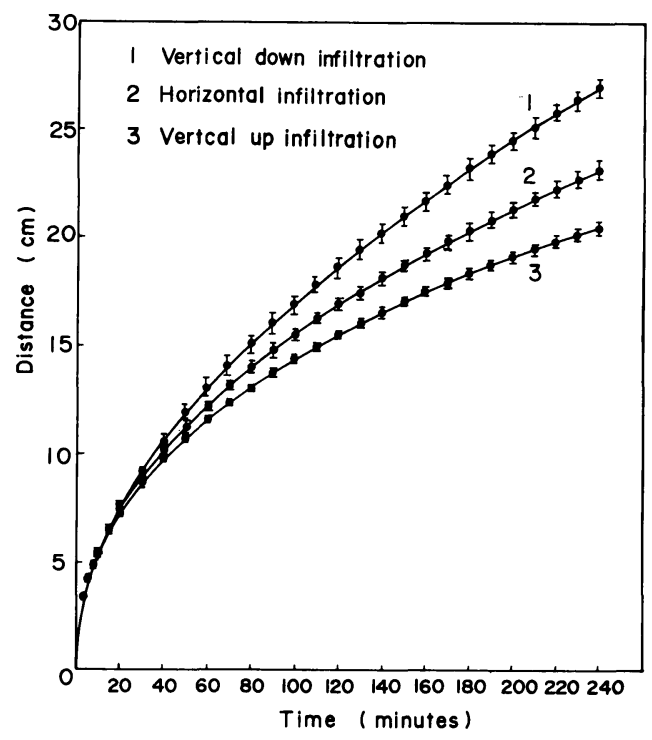

Fig. 2. Wetting front advancement during infiltration.

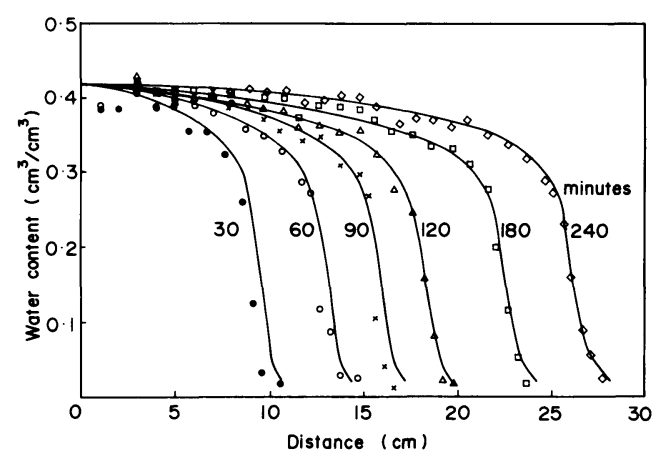

Fig. 4. Soil water content distributions for vertical-down infiltration. Solid curves were calculated from eq. (10).

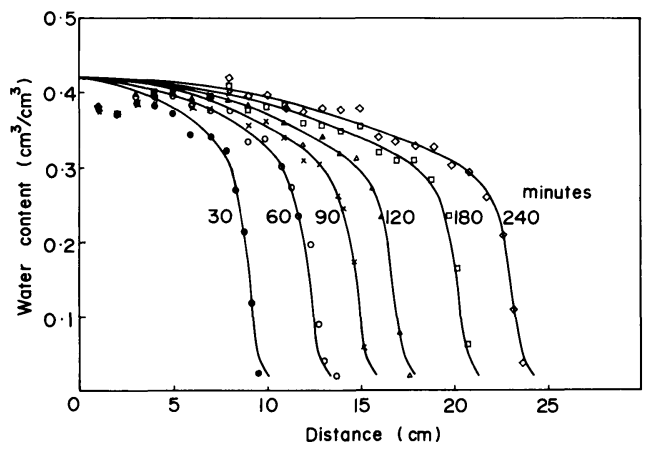

Fig. 3. Soil water content distributions for horizontal infiltration. Solid curves were calculated from eq. (9).

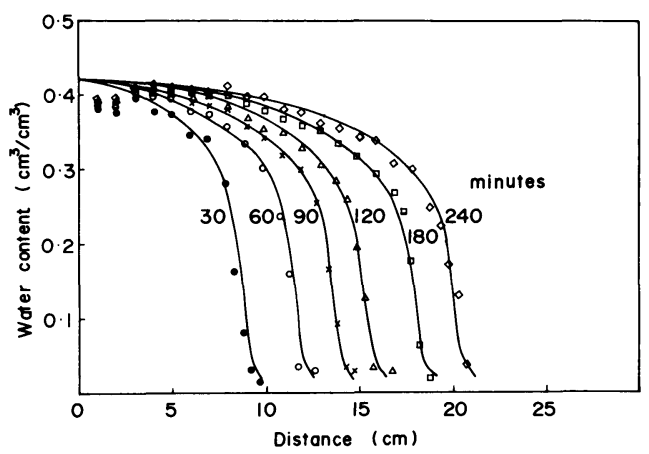

Fig. 5. Soil water content distributions for vertical-up infiltration. Solid curves were calculated from eq. (11). 


\section{Wetting front advancement and water content distribution}

Figure 2 shows the visual wetting front advancement during vertical-up, verticaldown, and horizontal infiltrations, with the standard deviations at each point. These standard deviations were calculated from three repetitive runs for each direction.

Table 3 shows the relation between the combinations of run numbers and the average standard deviations of the wetting front advancement. The average standard deviations were calculated by averaging the standard deviations at each 10 -minute distance of wetting fronts. Our skill in executing the experiments apparently increased with time, thus decreasing the average standard deviation. Only the last combinations in table 3 were chosen for figure 2 and for the analysis.

Figures 3, 4, and 5 show the soil water content distributions during infiltration. Each point indicates the average values of the three chosen columns. The solid lines in figures 3,4 , and 5 were calculated and will be discussed later.

Combining figure 2 with figures 3,4 , and 5 we can find the water content at the wetting fronts at each time. Table 4 shows the average soil water contents at the wetting front, and table 5 provides their statistical analysis. From the analysis of variance, the $F$

TABLE 3. AVERAGE STANDARD DEVIATIONS OF THE WETTING FRONT ADVANCEMENT

\begin{tabular}{lllll}
\hline $\begin{array}{l}\text { Direction of } \\
\text { infiltration }\end{array}$ & \multicolumn{2}{c}{ Run } & number & $\begin{array}{c}\text { Average standard } \\
\text { deviations }(\mathrm{cm})\end{array}$ \\
\hline Horizontal & 1 & 2 & 3 & 0.30 \\
\hline Vertical down & 1 & 2 & 3 & 0.65 \\
& 2 & 3 & 4 & 0.60 \\
& 3 & 4 & 5 & 0.45 \\
& 4 & 5 & 6 & 0.37 \\
\hline Vertical up & 1 & 2 & 3 & 0.44 \\
& 2 & 3 & 4 & 0.44 \\
& 3 & 4 & 5 & 0.16 \\
\hline
\end{tabular}

TABLE 4. AVERAGE SOIL WATER CONTENT $\left(\mathrm{cm}^{3} / \mathrm{cm}^{3}\right)$ AT THE WETTING FRONT

\begin{tabular}{cccc}
\hline \multirow{2}{*}{$\begin{array}{c}\text { Infiltration } \\
\text { time (minutes) }\end{array}$} & \multicolumn{3}{c}{ Direction of infiltration } \\
\cline { 2 - 4 } 30 & 0.141 & 0.133 & 0.150 \\
60 & 0.195 & 0.110 & 0.140 \\
90 & 0.125 & 0.095 & 0.125 \\
120 & 0.105 & 0.150 & 0.130 \\
180 & 0.140 & 0.107 & 0.120 \\
240 & 0.130 & 0.130 & 0.143 \\
\hline Mean & 0.139 & 0.121 & 0.135 \\
\hline Overal1 Mean & & 0.132 & \\
\hline
\end{tabular}


ratio of the water contents at the wetting front was 1.142 , which is so small that we conclude there are no differences among the values for downward, upward, and horizontal infiltration. In addition, from the regression analysis, correlation coefficients between infiltration time and water content at the wetting fronts are so small that we conclude there are no relations between them. Consequently, the water content at the wetting front can be defined here as $0.132 \mathrm{~cm}^{3} / \mathrm{cm}^{3}$.

TABLE 5. ANALYSIS OF VARIANCE OF THE DATA IN TABLE 4

\begin{tabular}{lcccc}
\hline $\begin{array}{l}\text { Source of } \\
\text { variation }\end{array}$ & $\begin{array}{l}\text { Sum of } \\
\text { squares }\end{array}$ & $\begin{array}{c}\text { Degree of } \\
\text { freedom }\end{array}$ & $\begin{array}{c}\text { Mean } \\
\text { square }\end{array}$ & $\begin{array}{c}\text { Computed } \\
\text { F }\end{array}$ \\
\hline Direction & 0.00111 & 2 & 0.000556 & 1.14 \\
Error & 0.00730 & 15 & 0.000486 & \\
\hline Total & 0.00841 & 17 & & \\
\hline
\end{tabular}

TABLE 6. RELATION BETWEEN $\mathrm{x}_{1}$ and $\theta$ DURING HORIZONTAL INFILTRATION, AND THE ESTIMATED VALUES OF $\theta$ and $\varepsilon_{1}$

\begin{tabular}{|c|c|c|c|c|c|c|c|c|c|}
\hline \multirow{2}{*}{$\mathrm{cm}^{3} / \mathrm{cm}^{3}$} & \multirow{2}{*}{$\frac{x_{1}}{30}$} & \multirow{2}{*}{$\frac{(\mathrm{cm}) \text { at }}{60}$} & \multirow{2}{*}{$\frac{\text { each }}{90}$} & \multirow{2}{*}{$\frac{\text { time }}{120}$} & \multicolumn{2}{|c|}{ (minutes) } & \multirow{2}{*}{$\begin{array}{c}\phi \\
\mathrm{cm} / \min ^{\frac{1}{2}}\end{array}$} & \multirow{2}{*}{$\begin{array}{l}\varepsilon_{1} \\
\mathrm{~cm}\end{array}$} & \multirow{2}{*}{$\begin{array}{c}\text { Correla- } \\
\text { tion } \\
\text { coef }\end{array}$} \\
\hline & & & & & 180 & 240 & & & \\
\hline \multicolumn{10}{|l|}{0.02} \\
\hline 0.04 & 9.5 & 13.1 & 15.3 & 17.4 & 20.9 & 23.6 & 1.4009 & 2.0232 & 0.9996 \\
\hline 0.06 & 9.5 & 12.9 & 15.1 & 17.3 & 20.7 & 23.5 & 1.3982 & 1.9100 & 0.9998 \\
\hline 0.08 & 9.4 & 12.8 & 15.0 & 17.1 & 20.6 & 23.4 & 1.3938 & 1.8481 & 0.9998 \\
\hline 0.10 & 9.3 & 12.7 & 15.0 & 17.0 & 20.5 & 23.3 & 1.3893 & 1.7945 & 0.9998 \\
\hline 0.12 & 9.2 & 12.6 & 14.9 & 16.9 & 20.4 & 23.2 & 1.3927 & 1.6594 & 0.9998 \\
\hline 0.14 & 9.1 & 12.5 & 14.8 & 16.8 & 20.3 & 23.1 & 1.3882 & 1.6059 & 0.9998 \\
\hline 0.16 & 9.0 & 12.5 & 14.7 & 16.6 & 20.2 & 23.0 & 1.3858 & 1.5307 & 0.9997 \\
\hline 0.18 & 8.9 & 12.4 & 14.6 & 16.5 & 20.1 & 22.8 & 1.3782 & 1.5049 & 0.9996 \\
\hline 0.20 & 8.8 & 12.2 & 14.6 & 16.4 & 20.0 & 22.7 & 1.3822 & 1.3273 & 0.9998 \\
\hline 0.22 & 8.7 & 11.9 & 14.3 & 16.2 & 19.8 & 22.5 & 1.3807 & 1.1675 & 0.9999 \\
\hline 0.24 & 8.6 & 11.6 & 14.2 & 16.1 & 19.6 & 22.2 & 1.3704 & 1.0733 & 0.9998 \\
\hline 0.26 & 8.4 & 11.4 & 13.8 & 15.8 & 19.2 & 21.8 & 1.3474 & 1.0153 & 0.9999 \\
\hline 0.28 & 8.2 & 11.2 & 13.4 & 15.5 & 18.9 & 21.2 & 1.3126 & 1.0378 & 0.9995 \\
\hline 0.30 & 8.0 & 10.8 & 12.9 & 15.0 & 18.2 & 20.1 & 1.2336 & 1.3179 & 0.9986 \\
\hline 0.32 & 7.9 & 10.4 & 11.5 & 13.8 & 16.0 & 19.2 & 1.1054 & 1.5968 & 0.9948 \\
\hline 0.34 & 7.1 & 8.9 & 10.9 & 12.3 & 15.5 & 16.2 & 0.9722 & 1.6526 & 0.9929 \\
\hline 0.36 & 5.5 & 8.4 & 9.4 & 11.0 & 12.0 & 15.5 & 0.9115 & 0.7979 & 0.9842 \\
\hline 0.38 & 4.4 & 6.4 & 8.5 & 10.2 & 10.0 & 10.9 & 0.6451 & 1.6635 & 0.9358 \\
\hline 0.40 & & & & & & 8.9 & 0.5713 & & \\
\hline 0.42 & & & & & & & 0 & & \\
\hline
\end{tabular}




\section{$x$ and $\sqrt{t}$ relation, and $\phi(\theta)$ values}

The so-called Boltzmann transformation written as eq. (6) is a mathematical consequence of the form of eq. (1) and the initial condition $\left(\theta=\theta_{i}, t=0, x_{1}>0\right)$ of conditions eq. (5). Figure 6 shows the $x$ and $\sqrt{t}$ relations at each water content during horizontal infiltration. The intercepts of the distance axis are equal to the error term $\varepsilon_{1}$ in eq. (9) and the slope of the regression lines can be regarded as $\phi$ values in the same equation. Table 6 gives the relations between time and distance where the water content is constant, the coefficients of linear regression lines for $\mathrm{x}_{1}$ versus $\sqrt{\mathrm{t}}$, and their correlation coefficients. We also found a significant correlation between $\varepsilon_{1}$ and $\theta$, having a slope of -1.89 , an intercept of 1.86 , and a correlation coefficient of -0.621 with 16 degrees of freedom. This means that although $\varepsilon_{1}$ was regarded as the random variable having a mean of zero, it is inversely related to $\theta$.

\section{$\chi(\theta)$ and $\psi(\theta)$ values}

The way to estimate $\chi(\theta)$ values from experimental data of water content during infiltration was shown by Nielsen and Vachaud (1965) for the first time. According to their method, we obtain from eqs. (9), (10), and (11)

$$
\begin{aligned}
& x_{2}-x_{1}=t x+t^{\frac{3}{2}} \psi+\varepsilon_{2} \\
& x_{1}-x_{3}=t x-t^{\frac{3}{2}} \psi-\varepsilon_{3}
\end{aligned}
$$

in which the error term $\varepsilon_{1}$ is eliminated.

Figure 7 shows the relation between $\left(x_{2}-x_{1}\right)$ and $t$, and $\left(x_{1}-x_{3}\right)$ and $t$, at the wetting front. If $\psi, \varepsilon_{2}$, and $\varepsilon_{3}$ values are negligibly small, these two lines should coincide. Statistically the 95 percent confidence intervals for the $\chi$ values are, respectively, $0.0160<\chi<0.0168$ and $0.0107<\chi<0.0115$. Hence, it is concluded that $\psi, \varepsilon_{2}$, and $\varepsilon_{3}$ cannot be neglected, and eqs. (28) and (29) are inadequate to estimate $\chi(\theta)$ values. The reason why Nielsen and Vachaud (1965) failed to obtain equal values of $\chi$ for vertical-up and vertical-down infiltration may be the same with this case.

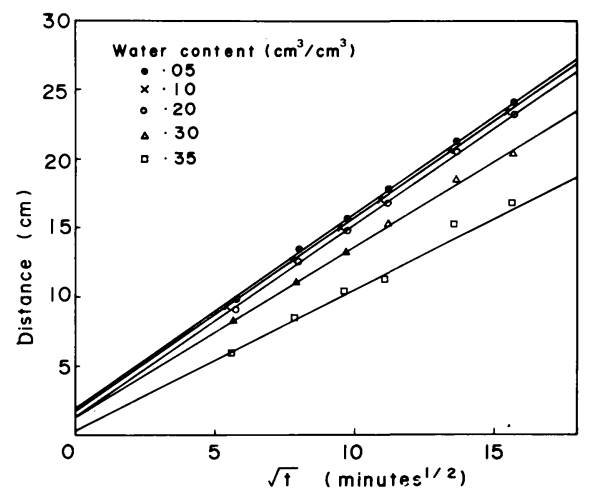

Fig. 6. Relation between the distance of the soil section where a given water content value is located and the square root of time during horizontal infiltration.

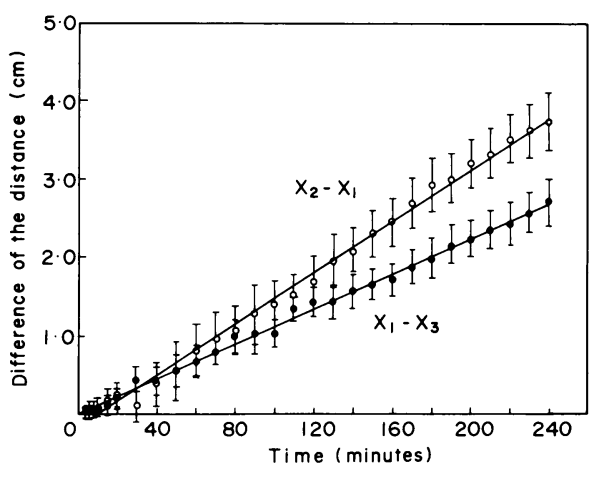

Fig. 7. Relation between $\left(x_{2}-x_{1}\right)$ and time, and $\left(x_{1}-x_{3}\right)$ and time at the wetting front. 
The next possible way to estimate $\chi(\theta)$ is to compare the water content distributions during vertical-up and -down infiltration. Subtracting eq. (11) from (10), we obtain

$$
x_{2}-x_{3}=2 t x+\varepsilon_{2}-\varepsilon_{3}
$$

in which $\varepsilon_{1}$ is again eliminated.

Figure 8 shows the relation between $\left(x_{2}-x_{3}\right)$ and $t$ at the wetting front. The regression coefficient is very high (0.999) and the intercept, which is regarded as the estimated value of $\left(\varepsilon_{2}-\varepsilon_{3}\right)$, is very small $(-0.169)$. Hence, it is expected that good estimations of $\chi$ can be obtained from the relation between $\left(x_{2}-x_{3}\right)$ and $t$ at each water content. Table 7 and table 8 give the relation between $x_{2}$ and $t$, and $x_{3}$ and $t$. Table 9 gives values of $\left(x_{2}-x_{3}\right)$ for given values of $\theta$ for different infiltration times $t$, their correlation coefficients, and estimates of $\chi$ values.

Using eqs. (9), (10), and (11), $\psi(\theta)$ values were calculated from the equation

$$
x_{2}+x_{3}-2 x_{1}=2 \psi t^{\frac{3}{2}}+\varepsilon_{2}+\varepsilon_{3}
$$

in which the error term $\varepsilon_{1}$ was eliminated. Table 10 gives the values of $\left(\mathrm{x}_{2}+\mathrm{x}_{3}-2 \mathrm{x}_{1}\right), \psi$, $\varepsilon_{2}+\varepsilon_{3}$ and their correlation coefficients for given values of $\theta$.

Figure 9 shows the $\phi, \chi$, and $\psi$ values as functions of water content.

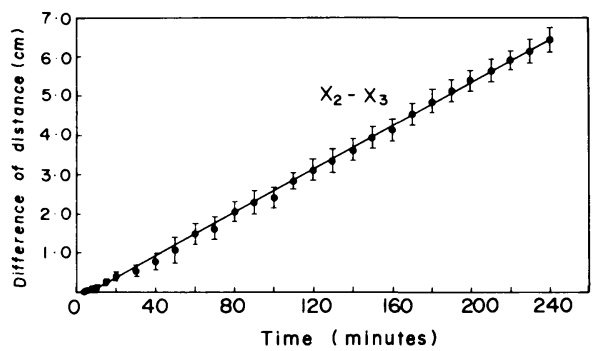

Fig. 8. The relation between $\left(x_{2}-x_{3}\right)$ and time at the wetting front.

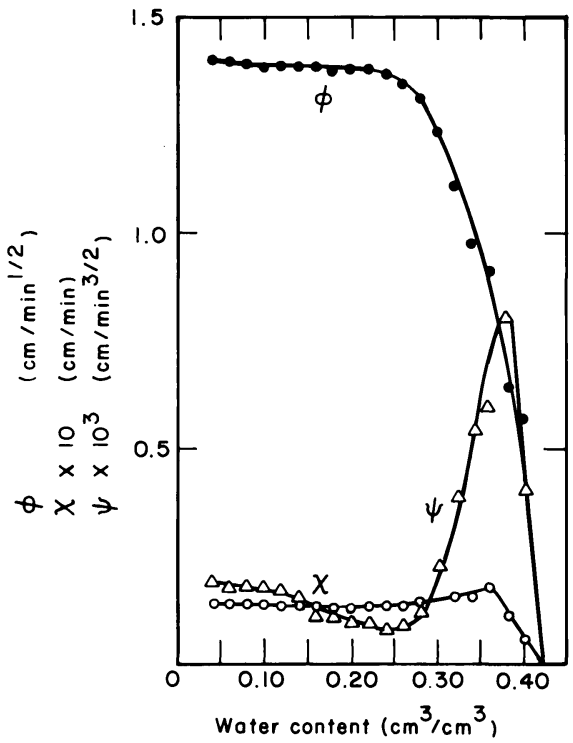

Fig. 9. Values of $\phi, \chi$ and $\psi$ defined by eq. (9), (10), and (11) vs soil water content. 


\section{Cumulative infiltration}

Figure 10 shows the cumulative infiltration I calculated from the water content distributions. It is also possible to estimate the three parameters of infiltration eq. (19) from these data. The experimental equations are

$$
\begin{aligned}
& I_{1}=M t^{\frac{1}{2}}+m_{1} \\
& I_{2}=M t^{\frac{1}{2}}+M^{\prime} t+M^{\prime \prime} t^{\frac{3}{2}}+m_{2} \\
& I_{3}=M t^{\frac{1}{2}}-M^{\prime} t+M^{\prime \prime} t^{\frac{3}{2}}+m_{3}
\end{aligned}
$$

for horizontal, vertical-down, and vertical-up infiltration, respectively. The terms $m_{1}$, $\mathrm{m}_{2}$, and $\mathrm{m}_{3}$ are the error terms. Table 11 shows the cumulative infiltration and the values of the parameters which were calculated by the least square method with $r$ being the correlation coefficient.

It is interesting to compare the values of the parameters shown in table 11 with the coefficients of eq. (19) which can be obtained by integrating the functions $\phi, \chi$, and $\psi$.

The integrated value of

$$
\left(\int_{\theta}^{\theta_{0}} \phi \mathrm{d} \theta\right)
$$

was calculated numerically by both Simpson's rule and the trapezoidal rule. The initial water contents $\theta_{\mathrm{i}}$ were $0.02 \sim 0.025 \mathrm{~cm}^{3} / \mathrm{cm}^{3}$, and $\phi\left(\theta_{\mathrm{i}}\right)$ must theoretically be infinite. To avoid complicated discussion, the numerical integration was carried out from $\theta=0.02$ $\mathrm{cm}^{3} / \mathrm{cm}^{3}$ to $0.42 \mathrm{~cm}^{3} / \mathrm{cm}^{3}$ assuming $\phi(0.002)=\phi(0.04)$. The integrated value was 0.4838 by Simpson's rule and 0.4826 by trapezoidal rule, which were very close to the value of $M=0.4764$. The integrated value of $\chi$

$$
\left(\int_{\theta_{i}}^{\theta} 0 x d \theta\right)
$$

was also calculated from $\theta=0.02 \mathrm{~cm}^{3} / \mathrm{cm}^{3}$ to $0.42 \mathrm{~cm}^{3} / \mathrm{cm}^{3}$, and was found to be 0.005297 by Simpson's rule and 0.005267 by trapezoidal rule, which were very close to the value of $\mathrm{M}^{\prime}=0.005373$.

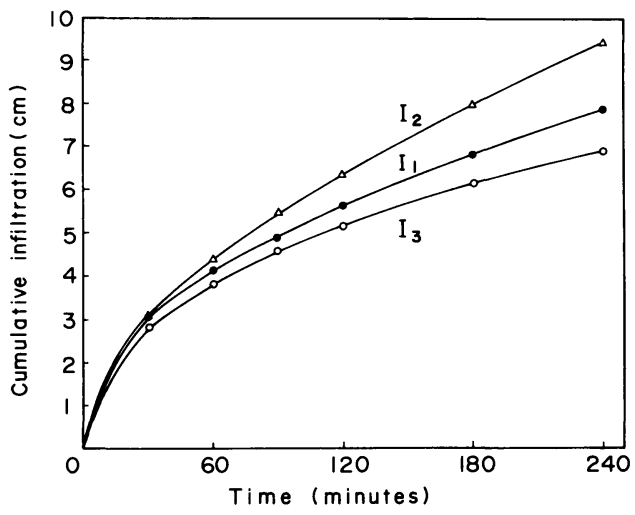

Fig. 10. Cumulative infiltration during horizontal $\left(\mathrm{I}_{1}\right)$, vertical-down $\left(\mathrm{I}_{2}\right)$, and vertical-up $\left(\mathrm{I}_{3}\right)$ infiltration. 

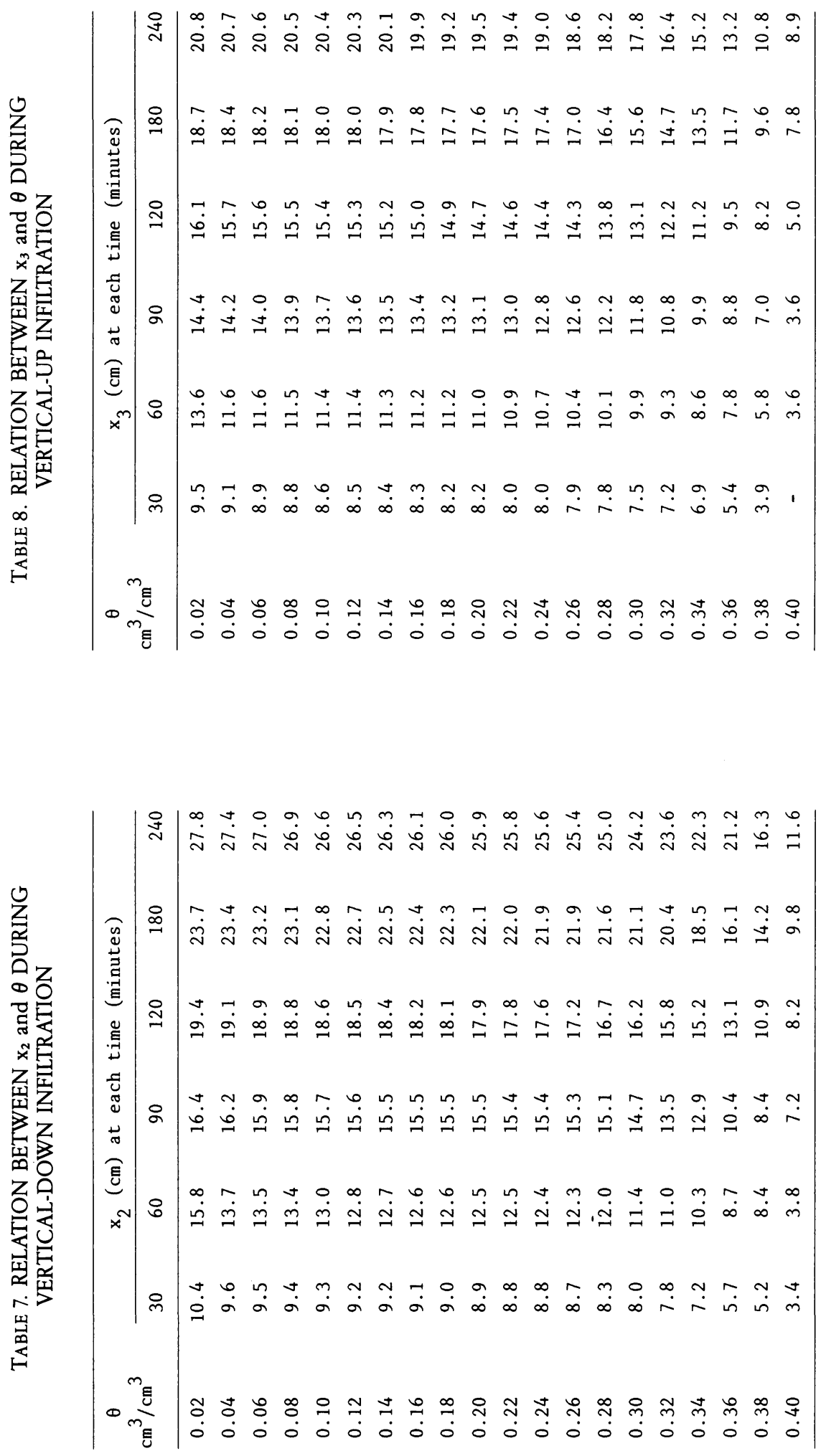


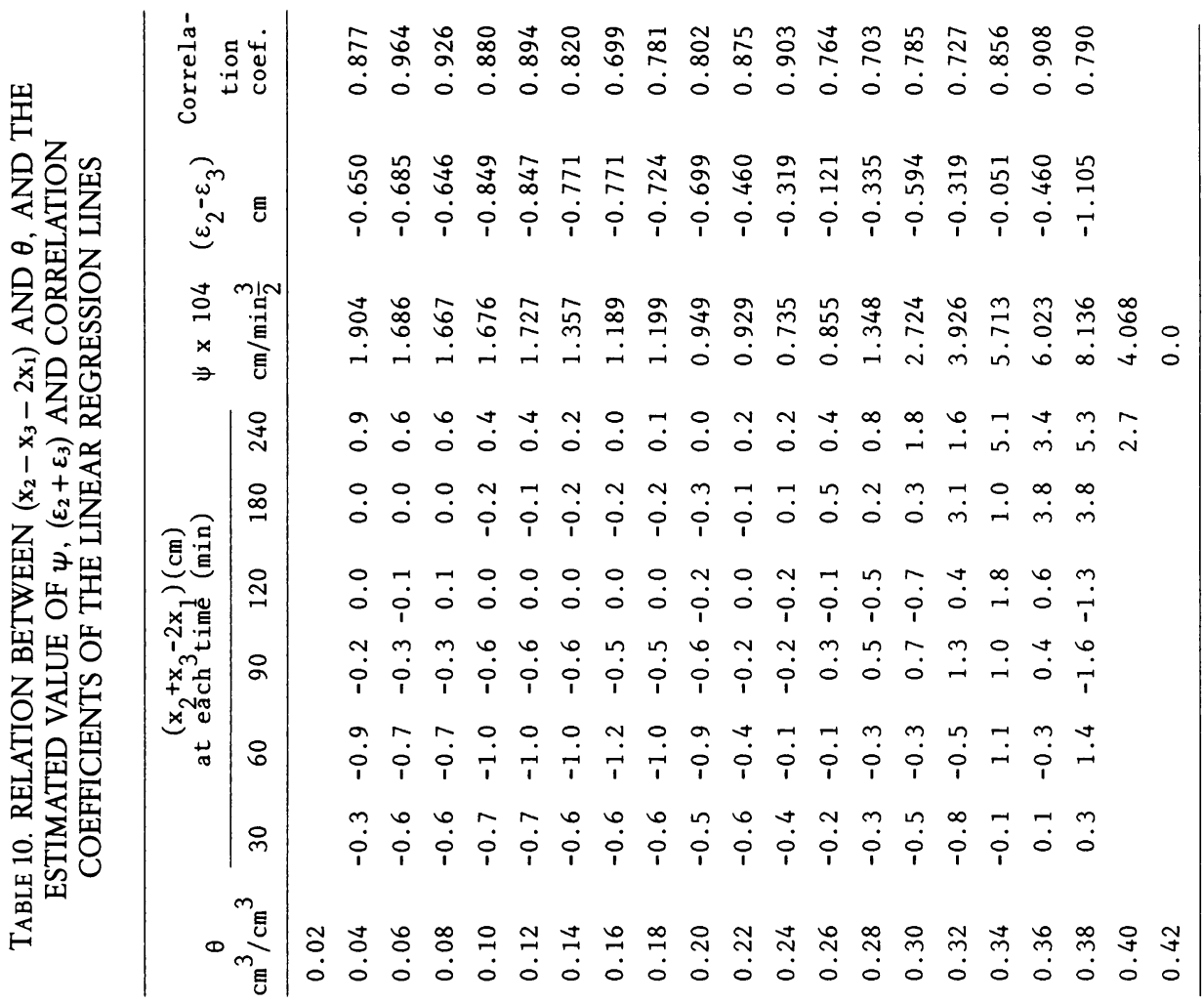

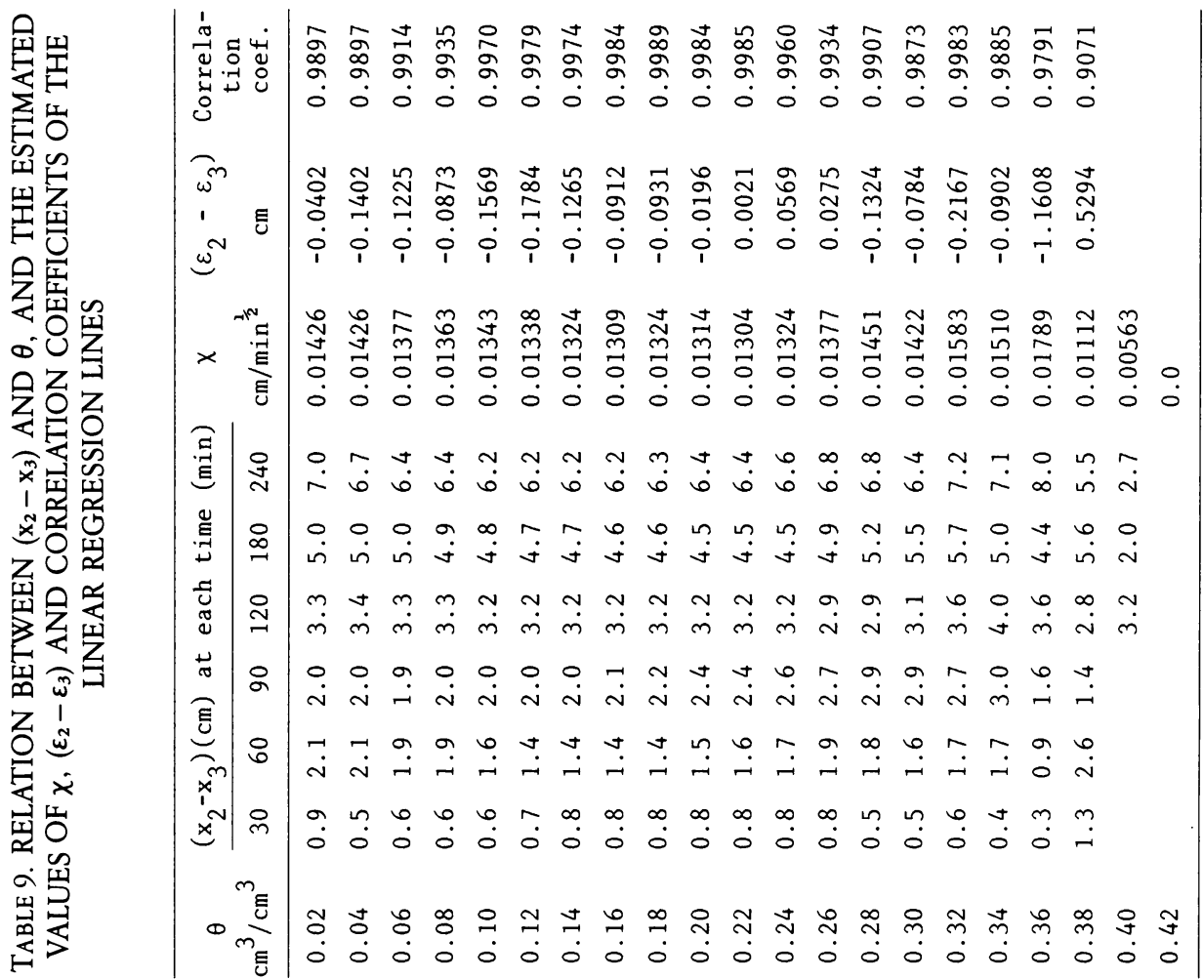


The integrated value of $\psi,\left(\int_{\theta_{i}}^{\theta_{0}} \psi \mathrm{d} \theta\right)$

was calculated to be $0.9640 \times 10^{-4}$ by Simpson's rule and $0.9523 \times 10^{-4}$ by trapezoidal rule, which were also very close to the value of $\mathrm{M}^{\prime \prime}=1.00 \times 10^{-4}$.

\section{Prediction of water content distribution}

In figures 3, 4, and 5, the solid lines were calculated from eqs. (9), (10), and (11) neglecting the error terms $\varepsilon_{2}$ and $\varepsilon_{3}$. All of the calculated distributions agree well with those measured. The maximum difference between measured and calculated water content is seen for small values of $\theta$ at 30 minutes during vertical-down infiltration for which the discrepancy is about $0.6 \mathrm{~cm}$. Obviously, error term $\varepsilon_{1}$ is not negligible.

\section{Estimation of $\mathbf{D}$ and $\mathbf{K}-\mathbf{K}_{\mathbf{i}}$}

When $\phi$ and $\chi$ values are given as functions of water content $\theta, \mathrm{D}$ and $\left(\mathrm{K}-\mathrm{K}_{\mathrm{i}}\right)$ values can be obtained from eqs. (14) and (16). For numerical integration, a reformed trapezoidal rule was applied to eqs. (14) and (16), which are given as

$$
D_{n+\frac{1}{2}}=-\frac{\phi_{n+1}-\phi_{n}}{2}\left[\frac{\phi_{2}-5 \phi_{1}}{8}+\sum_{k=1}^{n} \phi_{k}\right]
$$

TABLE 11. CUMULATIVE INFILTRATION AND VALUES OF THE PARAMETERS IN INFILTRATIONS EQS. (35), (36), AND (37), AND CORRELATION COEFFICIENTS r OF THE REGRESSION LINES

\begin{tabular}{|c|c|c|c|c|c|}
\hline $\begin{array}{c}\text { Time } \\
\text { (minutes) }\end{array}$ & $\begin{array}{l}\mathrm{I}_{1} \\
(\mathrm{~cm})\end{array}$ & $\begin{array}{c}\mathrm{I}_{2} \\
(\mathrm{~cm})\end{array}$ & $\begin{array}{c}\mathrm{I}_{3} \\
(\mathrm{~cm})\end{array}$ & $\begin{array}{r}\mathrm{I}_{2}-\mathrm{I}_{3} \\
(\mathrm{~cm})\end{array}$ & $\begin{array}{c}\mathrm{I}_{2}+\mathrm{I}_{3}-2 \mathrm{I} \\
(\mathrm{cm})\end{array}$ \\
\hline 30 & 3.04 & 3.07 & 2.83 & 0.24 & -0.18 \\
\hline 60 & 4.13 & 4.41 & 3.83 & 0.58 & -0.02 \\
\hline 90 & 4.88 & 5.45 & 4.57 & 0.88 & 0.26 \\
\hline 120 & 5.63 & 6.32 & 5.12 & 1.20 & 0.18 \\
\hline 180 & 6.78 & 7.96 & 6.12 & 1.84 & 0.52 \\
\hline 240 & 7.83 & 9.37 & 6.86 & 2.51 & 0.57 \\
\hline M & 0.4764 & & & & \\
\hline $\mathrm{m}_{1}$ & 0.4132 & & & & \\
\hline $\mathrm{r}$ & 0.9998 & & & & \\
\hline$M^{\prime}$ & & & & 0.005373 & \\
\hline $\mathrm{m}_{2}+\mathrm{m}_{3}$ & & & & -0.08108 & \\
\hline $\mathrm{r}$ & & & & 0.9999 & \\
\hline M" & & & & & 0.00010 \\
\hline$m_{2}+m_{3}-2 m_{1}$ & & & & & -0.07645 \\
\hline $\mathrm{r}$ & & & & & 0.9160 \\
\hline
\end{tabular}


$\left(\mathrm{K}-\mathrm{K}_{\mathrm{i}}\right)_{\mathrm{n}+\frac{1}{2}}=\left[\frac{\mathrm{x}_{2}-5 x_{1}}{8}+\sum_{\mathrm{k}=1}^{\mathrm{n}} \mathrm{x}_{\mathrm{k}}\right] \Delta \theta+\frac{1}{2}\left[\frac{x_{\mathrm{n}+1}-x_{\mathrm{n}}}{\phi_{\mathrm{n}+1}-\phi_{\mathrm{n}}}\right]\left[\frac{\phi_{2}-5 \phi_{1}}{8}+\sum_{\mathrm{k}=1}^{\mathrm{n}} \phi_{\mathrm{k}}\right] \Delta \theta$

where $\phi_{k}$ and $\chi_{k}$ are given in table 6 and table 9. The reformation of the trapezoidal rule was carried out in such a way that the integrations of $\theta_{k}$ and $\chi_{k}$ from $k=1$ to $k=n+1 / 2$, which are necessary to correspond the central differences of $n+1 / 2$, are possible.

Figure 11 shows the hydraulic diffusivity $\mathrm{D}$ as a function of water content. The empirical equation for these data is

$$
D=0.00124 \exp (21.1 \theta)
$$

with a correlation coefficient of 0.948 .

Figure 12 shows the relation between $\chi$ and $\phi$. Their least squares third-degree polynomial curve is given as

$$
x=0.0217 \phi^{2}(1.711-\phi)
$$

which was used to obtain the value of $d \chi / d \phi$ as a function of $\theta$. The calculated $\left(K-K_{i}\right)$ values are shown in figure 13 . The saturated hydraulic conductivity $\mathrm{K}_{\mathrm{s}}$ was measured to be $8.1 \times 10^{-3}\left( \pm 0.55 \times 10^{-3}\right) \mathrm{cm} / \mathrm{min}$. Figure 13 shows that the calculated $\left(\mathrm{K}-\mathrm{K}_{\mathrm{i}}\right)$ values at large water content values are close to the measured value of $\mathrm{K}_{s}$.

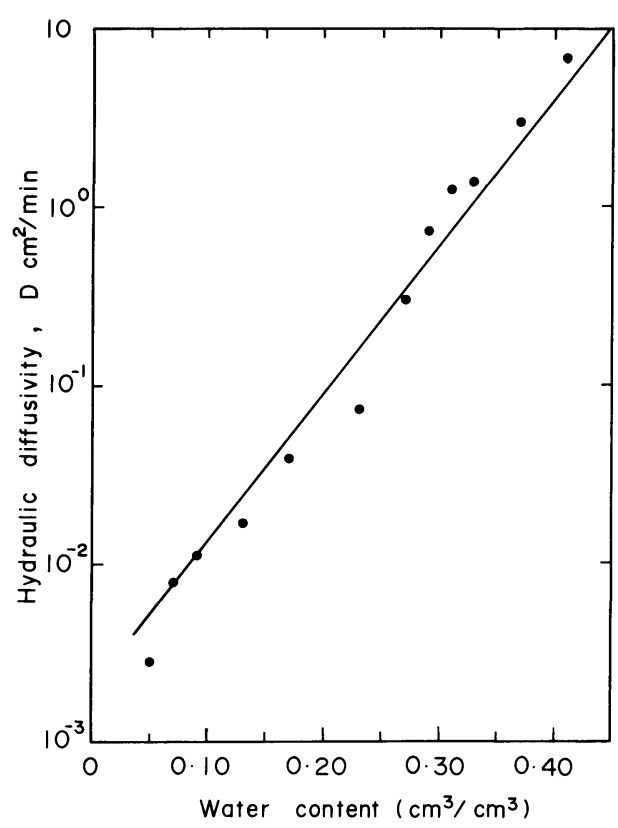

Fig. 11. Hydraulic diffusivity $\mathrm{D}$ vs water content of Hanford sandy loam.

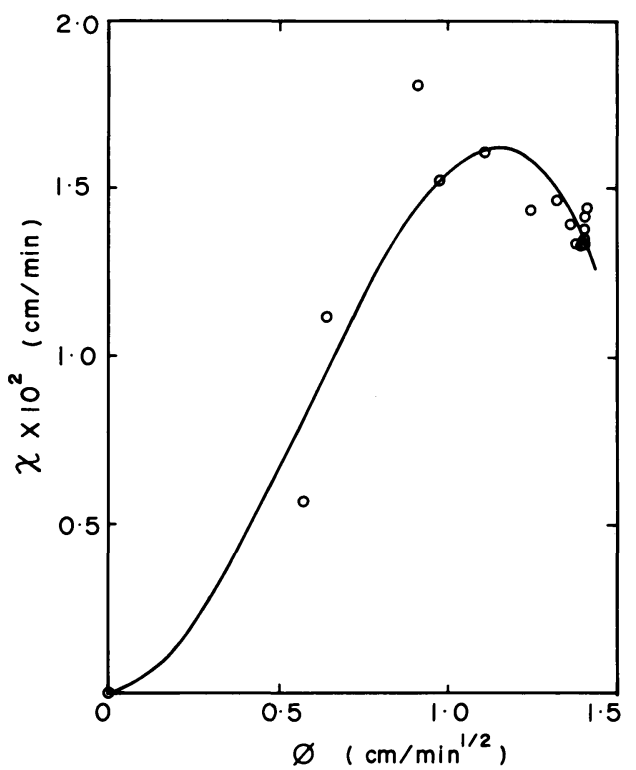

Fig. 12. Relation between $\chi$ and $\phi$ of Hanford sandy loam. The solid curve is the least squares third-degree polynomial. 
Figure 14 shows the soil water characteristic curve of Hanford sandy loam, obtained 24 days after the start of wetting of a $100-\mathrm{cm}$ vertical column from the bottom. From figures 11 and 14 , another estimation of $\mathrm{K}$ was calculated by eq. (4). To obtain the value of $\mathrm{d} \theta / \mathrm{dh}$ from figure 14 , a linear regression line was used between $\mathrm{h}=-30 \mathrm{~cm}$ and -70 $\mathrm{cm}$, having a slope of 0.004218 with a correlation coefficient of -0.987 . Combining this value of slope with eq. (40), the value of $\mathrm{K}$ was calculated and shown in figure 13, which appears to overestimate the values of $\mathrm{K}_{s}$ and $\mathrm{K}$. Twenty-four days may not be enough time to attain equilibrium for wetting within the column, and hence a value of $\mathrm{d} \theta / \mathrm{dh}$ is expected to be smaller than 0.004218 had equilibrium been attained.

\section{DISCUSSION}

Philip (1957a) showed the relation between the parameters $\phi, \chi, \psi, \omega$, and so on, and the hydraulic diffusivity $\mathrm{D}$ and hydraulic conductivity $\mathrm{K}$. Since then, based on known values of $\mathrm{K}(\theta)$ and $\mathrm{D}(\theta)$, close agreements between observed and calculated water content distributions have been obtained. On the other hand, few investigations have been made to estimate those parameters from measured water content distribution and to relate them to unknown values of $K(\theta)$ and $D(\theta)$.

Nielsen and Vachaud (1965) analyzed horizontal, vertical-down, and vertical-up infiltration of water into air-dry soil columns and presented the values of $\phi, \chi$, and $\psi$ vs soil water content. Although they predicted water content distribution during infiltration, they did not calculate the parameters $\mathrm{D}(\theta)$ and $\mathrm{K}(\theta)$.

The relation between $\phi(\theta)$ and $\mathrm{D}(\theta)$ is well known in the form of eq. (14). The relation between the parameters $\phi, \chi$, and $\mathrm{K}$ is written as eq. (16) which has never been

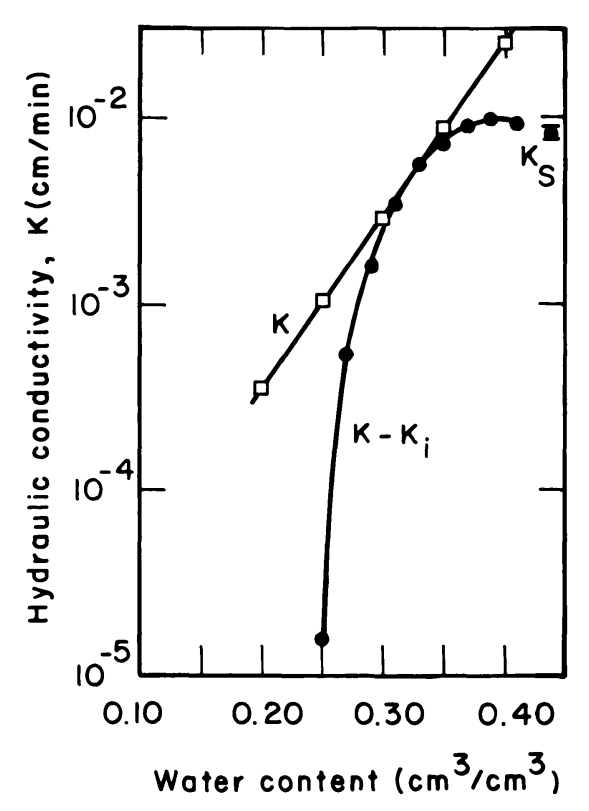

Fig. 13. Calculated $\mathrm{K}$ and $\left(\mathrm{K}-\mathrm{K}_{\mathrm{i}}\right)$, and measured $\mathrm{K}_{\mathrm{s}}$ vs water content of Hanford sandy loam.

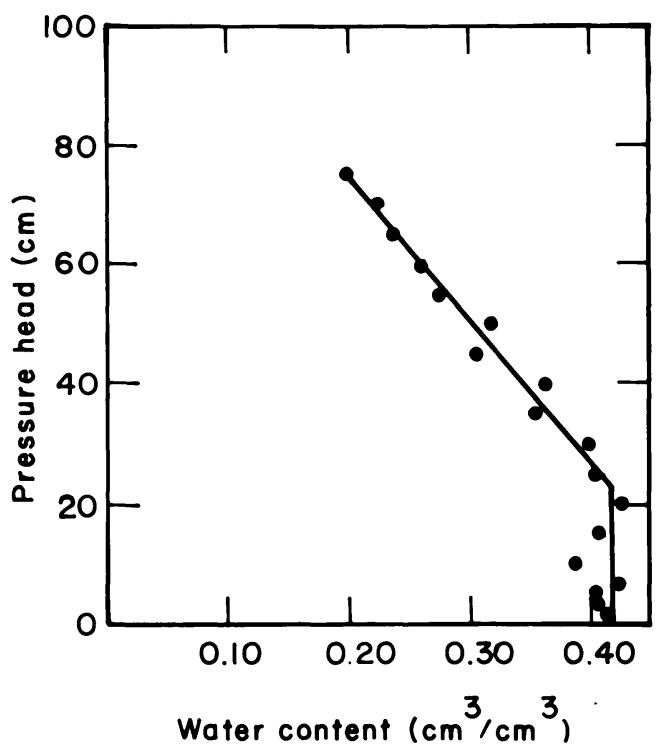

Fig. 14. Soil water characteristic curve of Hanford sandy loam. 
presented explicitly. Figures 15 through 22 show for different soils the previously published relations between $\chi$ and $\phi$ which were calculated from known $\mathrm{D}$ and $\mathrm{K}$, measured values of $\mathrm{K}$ and calculated $\left(\mathrm{K}-\mathrm{K}_{\mathrm{i}}\right)$ values vs water content which were obtained from eq. (39).

Philip (1957b) calculated values of the parameters $\phi, \chi, \psi$, and $\omega$ for Yolo light clay based upon Moore's experimental data of $\mathrm{D}(\theta)$ and $\mathrm{K}(\theta)$. Figure 15 shows the relations between $\chi$ and $\phi$, and figure 16 shows the calculated $\left(\mathrm{K}-\mathrm{K}_{\mathrm{i}}\right)$ values with measured $\mathrm{K}$ values. The fitted third-degree polynomial of the relation between $\phi\left(\mathrm{cm} / \mathrm{sec}^{1 / 2}\right)$ and $\chi(\mathrm{cm} / \mathrm{sec})$ is

$$
x=0.187 \phi\left(\phi^{2}-0.176 \phi+0.00840\right)
$$

with the multiple correlation coefficient of $r=0.998$, which is shown as the solid line in figure 15 . The agreement of the calculated $\left(\mathrm{K}-\mathrm{K}_{\mathrm{i}}\right)$ values with measured $\mathrm{K}$ values is good, suggesting that eq. (39) is sufficient to estimate $K(\theta)$ values neglecting $K_{i}$ for this soil.

Nielsen, Kirkham, and van Wijk (1961) calculated values of the parameters $\phi, \chi, \psi$, and $\omega$ vs water content for Monona silt loam and Ida silt loam based upon known values of $\mathrm{D}(\theta)$ and $\mathrm{K}(\theta)$. Figures 17 and 19 show the relations between $\chi$ and $\phi$ for both soils and figures 18 and 20 show the calculated $\left(\mathrm{K}-\mathrm{K}_{\mathrm{i}}\right)$ values with eq. (39). The fitted

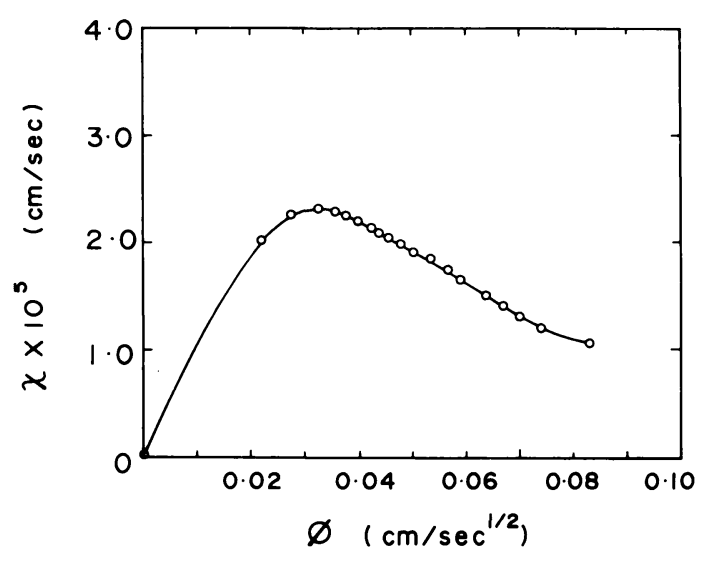

Fig. 15. Relation between $\chi$ and $\phi$ for Yolo light clay.

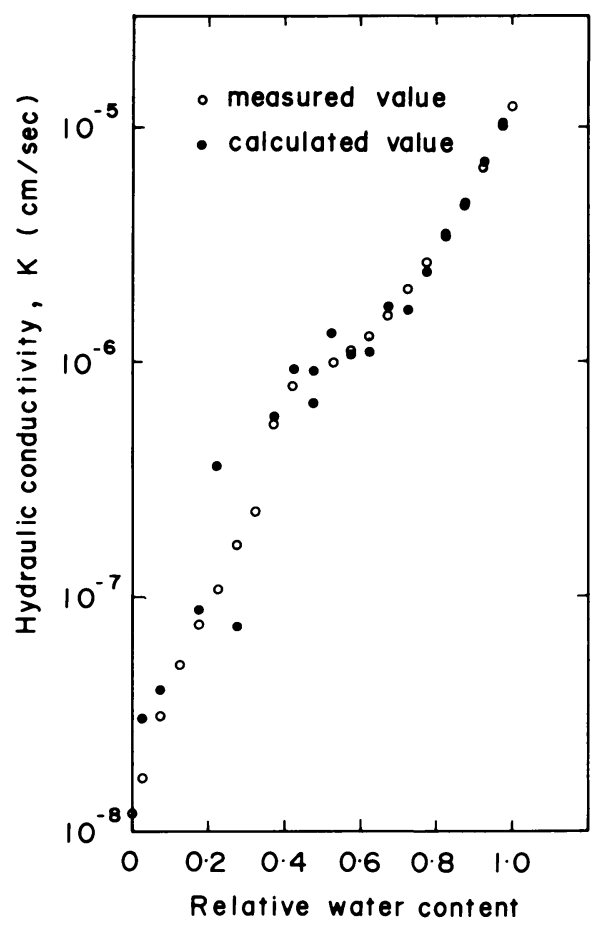

Fig. 16. Measured and calculated hydraulic conductivity of Yolo light clay. 
third-degree polynomial of the relation between $\phi\left(\mathrm{cm} / \mathrm{hr}^{1 / 2}\right)$ and $\chi(\mathrm{cm} / \mathrm{hr})$ for Monona silt loam is

$$
x=0.0313+1.15 \phi-0.0280 \phi^{2}+0.000114 \phi^{3}
$$

with the multiple correlation coefficient of $r=0.999$ and that for Ida silt loam is

$$
x=-0.0156+0.756 \phi-0.0233 \phi^{2}+0.000114 \phi^{3}
$$

with the multiple correlation coefficient of $r=0.997$, which are shown as the solid lines in figures 17 and 19. The measured $\mathrm{K}$ values and calculated $\left(\mathrm{K}-\mathrm{K}_{\mathrm{i}}\right)$ values agree especially well for large water content values, which again support the utility of eq. (39) for those soils.

Nielsen and Vachaud (1965) obtained different $\chi(\theta)$ values depending on the directions of vertical infiltration. Figures 21 and 22 show only the values of upward infiltration because almost all the calculated $\left(\mathrm{K}-\mathrm{K}_{\mathrm{i}}\right)$ values were negative in case of downward infiltration, which may be caused by the underestimation of $\mathrm{d} \chi / \mathrm{d} \phi$. The fitted thirddegree polynomial of the relation between $\phi\left(\mathrm{cm} / \mathrm{min}^{1 / 2}\right)$ and $\chi(\mathrm{cm} / \mathrm{min})$ for Columbia

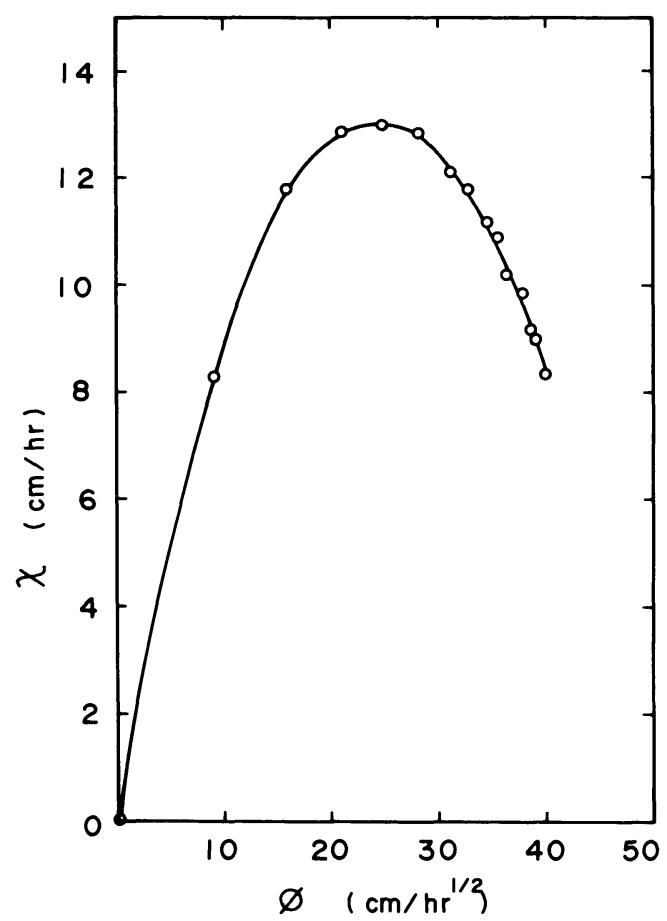

Fig. 17. Relation between $\chi$ and $\phi$ for Monona silt loam.

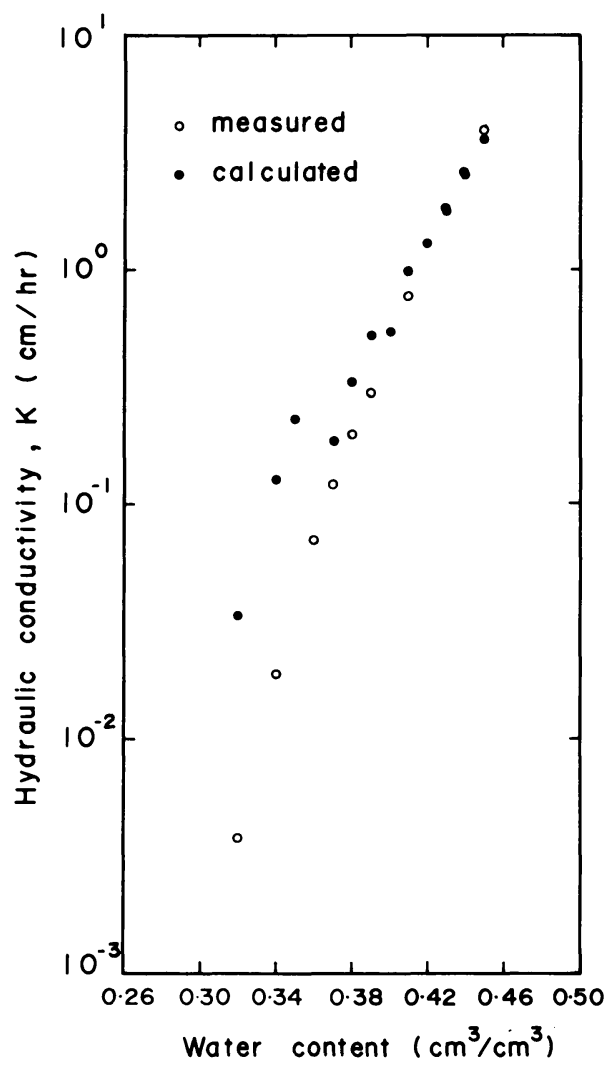

Fig. 18. Measured and calculated hydraulic conductivity of Monona silt loam. 
silt loam fails to show a positive value of $d \chi / d \phi$ at the origin. The fitted two-degree polynomial of the relation between $\phi$ and $\chi / \phi$ is

$$
x=\phi \times 10^{-4}\left(-0.116+7.895 \phi-4.603 \phi^{2}\right)
$$

with the multiple correlation coefficient of $r=0.926$, which is shown as the solid line in figure 21 .

Table 12 shows the values of $\mathrm{K}_{\mathrm{O}}, \mathrm{S}, \int_{\theta_{\mathrm{\theta}}}^{\theta} \mathrm{O} \chi \mathrm{d} \theta, \mathrm{A}$, and $\mathrm{A} / \mathrm{K}_{\mathrm{O}}$ for several kinds of soils. To calculate the values of $A$ by eq. (23), the slopes of the straight lines between the origin and the closest points to the origin in $\theta-\chi$ plane were used for the values of $d \chi / d \phi$ at $\theta=\theta_{0}$. As the functional relation between $\phi$ and $\chi$ is still not clear, it may be reasonable to evaluate it by discrete data in the meantime. In table 12 , the integrated values of $\chi$, which were calculated by Simpson's rule, are very close to the values of $A$. This means that it is possible to get the value of $A$ from both eqs. (23) and (21) neglecting $K_{i}$. It is convenient for us to be able to calculate the values of $A$ from $K_{0}, \phi$, and $\chi$ without knowing $\mathrm{K}_{\mathrm{i}}$ values.

The special merit of the above-mentioned technique is that from water distribution data during horizontal, vertical-up, and vertical-down infiltration, we can predict the water content distribution of different times, calculate the values of the physical parameters $\mathrm{D}(\theta)$ and $\mathrm{K}(\theta)$ and obtain the values of the parameters of the infiltration equation.

The efficiency of this method depends on the reliability of the values $\phi(\theta)$ and $\chi(\theta)$. Through theoretical consideration, good estimation of $\chi(\theta)$ values were expected by eq. (33), and figure 8 and table 9 revealed it to be true. On the other hand, the error term $\varepsilon_{1}$

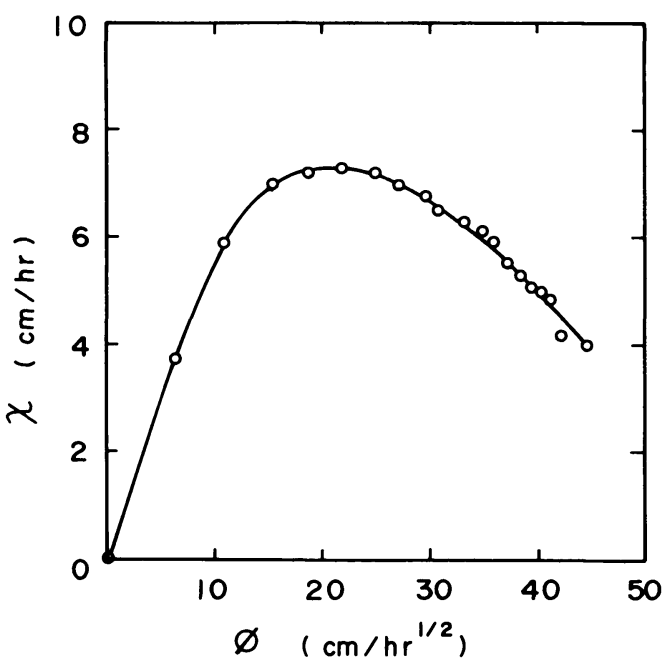

Fig. 19. Relation between $\chi$ and $\phi$ for Ida silt loam.

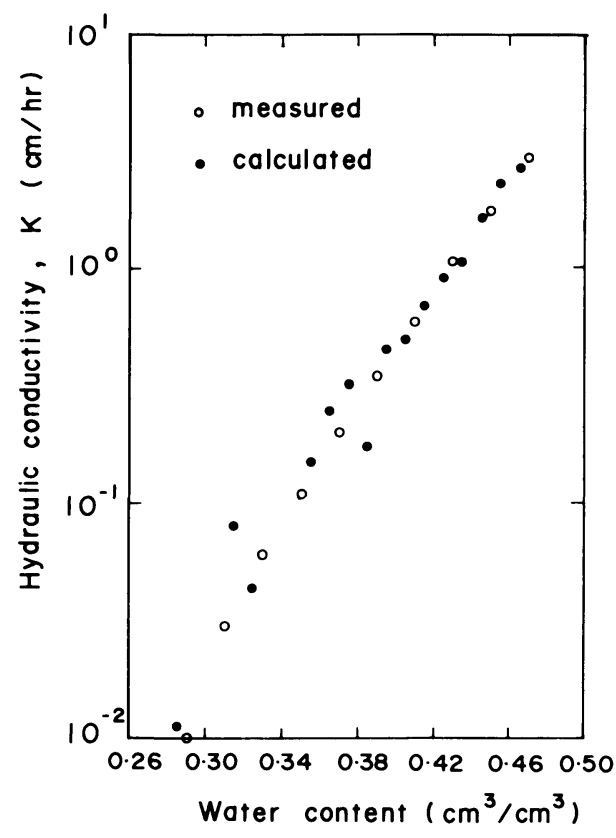

Fig. 20. Measured and calculated hydraulic conductivity of Ida silt loam. 
was so large that the question of the validity of Buckingham-Darcy's law for infiltration problems still remained. The effect of the soil bulk density, the effect of experimental skill of the investigator, and the effect of the low pressure at the entrance of each column were avoided as far as possible. Distilled water may cause both solute and air to be dissolved at the wetting front. The effect of heat on wetting is still in question. The fact that the error term $\varepsilon_{1}$ is in inverse proportion to $\theta$ raises the question whether Buckingham-Darcy's law is valid or not for infiltration into air-dry soil.

Another problem is the somewhat complicated procedure to determine $\phi(\theta)$ and $\chi(\theta)$ experimentally. There are two methods to determine the value of $\phi(\theta)$. The first, water content distribution is measured at a fixed time, which may be called the profile method. The second, water content is measured at a fixed position, which may be called the transient method. Selim, Kirkham, and Amemiya (1970) showed that both are reliable and the transient method is quicker and more convenient for computer analysis of data. In this study, although both $\phi(\theta)$ and $\chi(\theta)$ were determined by the profile method, it may be worthwhile to investigate whether the transient method is reliable, quick, and convenient to determine $\chi(\theta)$ or not. To determine $\chi(\theta)$ by the transient method, the experimental equations must be written as

$$
\begin{aligned}
& x=t_{1}^{\frac{1}{2}} \phi+\varepsilon_{1} \\
& x=t_{2}^{\frac{1}{2}} \phi+t_{2} x+t_{2}^{\frac{3}{2}} \psi+\varepsilon_{1}+\varepsilon_{2} \\
& x=t_{3}^{\frac{1}{2}} \phi-t_{3} x+t_{3}^{\frac{3}{2}} \psi+\varepsilon_{1}+\varepsilon_{3}
\end{aligned}
$$

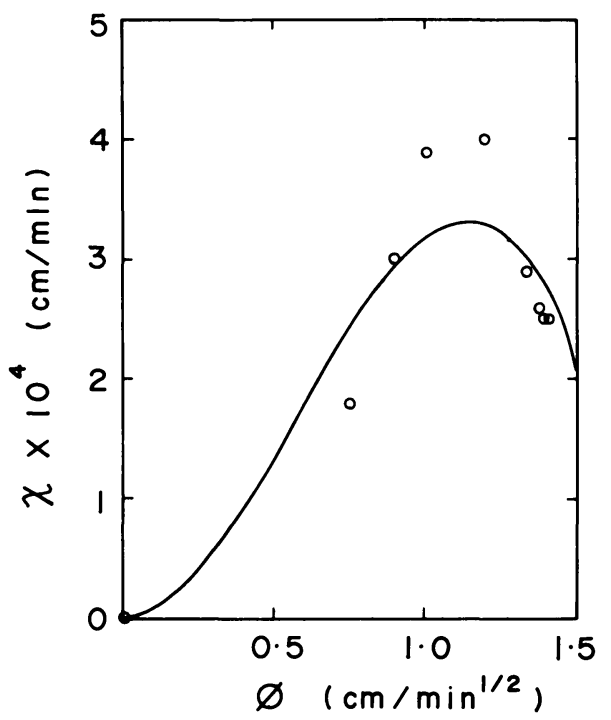

Fig. 21. Relation between $\chi$ and $\phi$ for Columbia silt loam. Solid line is the least squares thirddegree polynomial curve.

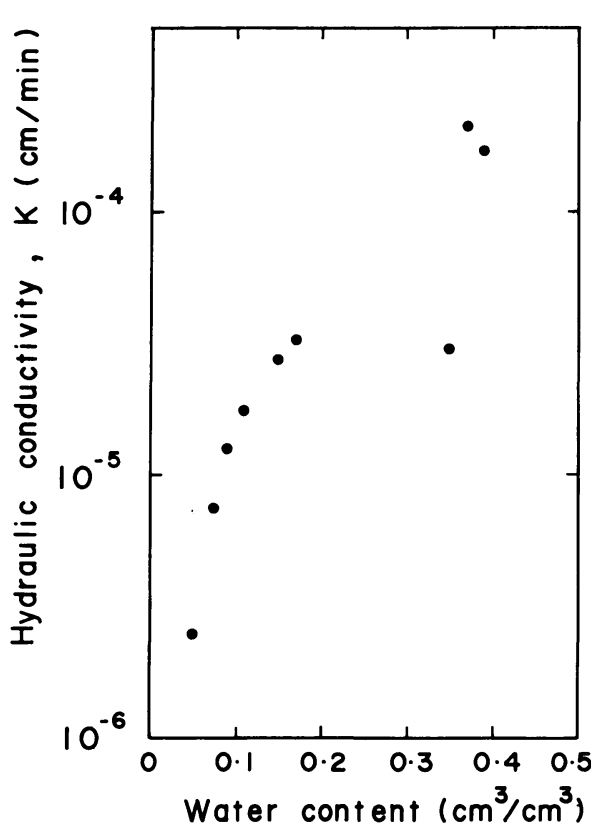

Fig. 22. Calculated hydraulic conductivity of Columbia light clay. 
for horizontal, vertical-down and vertical-up infiltrations, respectively. The times $t_{1}, t_{2}$, and $t_{3}$ are when the given value of $\theta$ passes across the position $x$. Random error variables $\varepsilon_{1}, \varepsilon_{2}$, and $\varepsilon_{3}$ fluctuate about an expected value of zero. In this case, $\chi(\theta)$ value can be calculated by eliminating $\phi$ and $\psi$ from eqs. (46), (47), and (48) as

$$
x=\frac{x-\varepsilon_{1}}{t_{2}^{-\frac{1}{2}}+t_{3}^{-\frac{1}{2}}}\left[t_{2}^{-\frac{3}{2}}-t_{3}^{-\frac{3}{2}}-t_{1}^{-\frac{1}{2}}\left(t_{2}^{-1}-t_{3}^{-1}\right)\right]-\frac{1}{t_{2}{ }^{-\frac{1}{2}}+t_{3}{ }^{-\frac{1}{2}}}\left[\frac{\varepsilon_{2}}{\frac{3}{2}}-\frac{\varepsilon_{3}}{t_{2}} t_{3}^{\frac{3}{2}}\right]
$$

The merit of this transient method is that we do not need such a correction as eq. (29) used in the profile method.

Although we tried the transient method for several times, we did not succeed in finding reproducible and reliable values of $\chi(\theta)$. This may be caused by the sensitivity of the relation between $\chi, t$, and $\mathrm{x}$ in eq. (49).

The accuracy of the estimation of $K(\theta)$ using eq. (16) depends on the accuracies of the values of

$$
\int_{\theta_{i}}^{\theta} x d \theta, \quad \int_{\theta_{i}}^{\theta} \phi d \theta \text { and }(d x / d \phi)_{\theta} .
$$

Figures 16,18 , and 20 proved that good estimation of $\mathrm{D}(\theta)$ and $\mathrm{K}(\theta)$ can be obtained using calculated $\phi(\theta)$ and $\chi(\theta)$ values, which were estimated from measured $\mathrm{D}(\theta)$ and $\mathrm{K}(\theta)$. In this case, the relation between $\chi$ and $\phi$ appears reasonable. On the other hand, the relation between $\chi$ and $\phi$ is more erratic when estimated from measured water content distributions. Figures 12 and 21 show that the third-degree polynomial curve remains somewhat approximate. Additional experimental studies involving different values of $\theta_{\mathrm{i}}$ and $\theta_{0}$ for a variety of soils are necessary to improve this method.

TABLE 12. VALUES OF $\mathrm{K}_{\mathrm{o}}, \mathrm{S}, \int_{\theta_{\mathrm{i}}}^{\theta_{0}} \chi \mathrm{d} \theta, \mathrm{A}$ and $\mathrm{A} / \mathrm{K}_{\mathrm{o}}$ FOR SEVERAL KINDS OF SOILS

\begin{tabular}{lcccccc}
\hline \multicolumn{1}{c}{ Soil } & $\mathrm{K}_{\mathrm{o}}$ & $\mathrm{S}$ & $\mathrm{F}$ & $\mathrm{A}$ & $\mathrm{A} / \mathrm{K}_{\mathrm{O}}$ & References \\
\hline Yolo light clay & $7.37 \times 10^{-4}$ & $9.71 \times 10^{-2}$ & $2.79 \times 10^{-4}$ & $2.80 \times 10^{-4}$ & 0.380 & Philip (1969a) \\
Monona silt loam & $6.02 \times 10^{-2}$ & $5.72 \times 10^{-2}$ & $2.62 \times 10^{-2}$ & $2.62 \times 10^{-2}$ & 0.435 & Nielsen (1961) \\
Ida silt loam & $4.50 \times 10^{-2}$ & $7.11 \times 10^{-1}$ & $1.82 \times 10^{-2}$ & $1.82 \times 10^{-2}$ & 0.403 & Nielsen (1961) \\
Columbia silt loam & $1.72 \times 10^{-4}$ & $4.68 \times 10^{-1}$ & $9.75 \times 10^{-5}$ & $9.75 \times 10^{-5}$ & 0.566 & $\begin{array}{l}\text { Nielsen and } \\
\text { Vachaud (1965) }\end{array}$ \\
Hanford sandy loam & $8.01 \times 10^{-3}$ & $4.84 \times 10^{-1}$ & $5.30 \times 10^{-3}$ & $5.63 \times 10^{-3}$ & 0.703 & This paper \\
\hline
\end{tabular}

$1 / \mathrm{K}_{\mathrm{o}}, \mathrm{F}$ and $\mathrm{A}$ are given in $\mathrm{cm} / \mathrm{min}$ and $\mathrm{S}$ is given in $\mathrm{cm} / \mathrm{min}^{\frac{1}{2}}$.

2/ $F=\int_{\theta_{i}}^{\theta}{ }^{0} \chi d \theta$ and $A$ is defined by eq. (21). 


\section{SUMMARY AND CONCLUSION}

Water content distributions during horizontal, vertical-up, and vertical-down infiltration into air-dry soil were measured experimentally using gamma radiation attenuation equipment. The data were analyzed using eqs. (9), (10), and (11). The parameters $\phi, \chi$, and $\psi$ were estimated through the least squares method. The relation between these parameters and $\mathrm{K}(\theta)$ was investigated theoretically to obtain eq. (16). The second parameter $A$ of the three-parameter infiltration eq. (19) was reduced to eq. (23). Estimated values of $K(\theta)$ and $A$ from eqs. (39) and (23) agreed well with experimental values.

Further studies into the reasons for the large values of $\varepsilon_{1}$ and somewhat erratic relation between the parameters $\chi$ and $\phi$ are necessary.

1. We wish to acknowledge the helpful discussions with Dr. Dale Swartzendruber (Purdue University) that allowed us to use eq. (29) to more accurately describe the soil water content profiles.

\section{LITERATURE CITED}

FRITTON, D. D.

1969. Resolving time, mass absorption coefficient and water content with gamma-ray attenuation. Soil Sci. Soc. Am. Proc., 33:651-655.

NIELSEN, D. R., D. KIRKHAM, and W. R. VAN WIJK.

1961. Diffusion equation calculations of field soil water infiltration profiles. Soil Sci. Sqc. Am. Proc., 25:165-168.

NIELSEN, D. R. and G. VACHAUD.

1965. Infiltration of water into vertical and horizontal soil columns. J. Indian Soc. Soil Sci. 13:15-23.

PHILIP, J. R.

1955. Numerical solution of equation of the diffusion type with diffusivity concentration-dependent. Trans. Faraday Soc. 51:885-892.

1957a. Numerical solution of equation of the diffusion type with diffusivity concentration-dependent. Australian J. Phys. 10:29-42.

1957b. The theory of infiltration; 1 . The infiltration equation and its solution. Soil Sci. 83:345-357.

1969a. Theory of infiltration. Adv. Hydrosci. 5:215-290.

$1969 \mathrm{~b}$. The dynamics of capillary rise. Proc. Symposium "Water in the Unsaturated Zone," Wageningen (1966), IASH/UNESCO, II. 559-564.

REGINATO, R. J., and C. H. M. VAN BAVEL.

1964. Soil water measurement with gamma attenuation. Soil Sci. Soc. Am. Proc., 28:721-724.

SELIM, H. M., D. KIRKHAM, and M. AMEMIYA.

1970. A comparison of two methods for determining soil water diffusivity. Soil Sci. Soc. Am. Proc., 34:14-18

YOUNGS, E. G.

1957. Moisture profiles during vertical infiltration. Soil Sci. 84:283-290. 